\section{Youth awareness on sexually transmitted infections, HIV and AIDS in secondary schools in the Dschang Municipality (Cameroon): the Mobile Caravan Project}

\author{
Martin Sanou Sobze, ${ }^{1}$ \\ Armand Tsapi Tiotsia, \\ Ghyslaine Bruna Djeunang Dongho, 2 \\ Guy Aurelien Foaleng Tankui, ${ }^{1}$ \\ Joseph Fokam, ${ }^{3-5}$ Kien-Atsu Tsi, ${ }^{1}$ \\ Jimmy Roger Fotso, ${ }^{1}$ \\ Yannick Ngueko Azeufack, 1,4,6 \\ Patrick Pete Nkamedjie, ${ }^{7}$ \\ Adogaye Ben Bechir Sali, ${ }^{8}$ \\ Rodrigue Biguioh Mabvouna, ${ }^{8}$ \\ Lucia Ercoli, 6,9 Vittorio Colizzi, \\ Gianluca Russo²
}

1Department of Biomedical Sciences, University of Dschang, Cameroon; 2Department of Infectious Diseases, Microbiology and Public Health, La Sapienza University of Rome, Italy; ${ }^{3}$ Chantal BIYA International Reference Centre for Research on HIV/AIDS

Prevention and Management, Yaoundé, Cameroon; ${ }^{4}$ Department of Experimental Medicine and Surgery, Tor Vergata University of Rome, Italy; ${ }^{5}$ Faculty of Medicine and Biomedical Sciences, University of Yaoundé I, Yaoundé, Cameroon; 'Institute of Medicine Solidale (IMES), Rome, Italy; ${ }^{7}$ Institute for

Research, Socio-economic Development and Communication (IRESCO), Yaoundé, Cameroon; ${ }^{8}$ Department of Biology, Tor Vergata University of Rome, Italy; ${ }^{9}$ Department of Biological Sciences, Tor Vergata University of Rome, Italy

\section{Abstract}

Awareness is a preventive action to instill in individuals certain concepts to improve their health. It is an essential element in the prevention of sexually transmitted infection (STI)/HIV and early pregnancies among adolescents. In 2012, the prevalence of HIVin Cameroon was estimated at $4.3 \%$. The young population appear to be the most affected (3.2\%); very close to that of the Dschang Health District (Cameroon; 3.1\%) in the 15-19 years age group. Theaimof this study was to evaluate the contribution of the Mobile Caravan project on the preventive aspect of STI/HIV/AIDS among youths of Dschang in 10 secondary schools within three years. 2029 students joined the project's activities and $58.55 \%$ of them belonged to the age group of 16-21 years. Most students attended private schools. Nearly 3/4 of students (1515/2029) had an acceptable level of knowledge regarding STI/HIV/AIDS, which increased in number each year (from 641 to 716 students between 2012 and 2014). The Level of knowledge was significantly determinedby the study cycle $(\mathrm{P}=0.0004)$, the type of school $(\mathrm{P}=0.0027)$ and the year ofimplementation of activities $(\mathrm{P}=0.0026)$. The caravan project has greatly contributed to improving young peoples' awareness on STI/HIV/AIDS in Dschang Municipality.

\section{Introduction}

Awareness is the process of instilling information, learning as an individual or group of individuals. ${ }^{1}$ Many authors recognize its importance as a technique of prevention and education for behavior change mainly related to STI's/HIV and AIDS..$^{2-10}$ It is used in health programs with a set of tasks and activities organized around specific goals to reduce the importance of a health problem, or interconnected problems. ${ }^{11}$ The $4^{\text {th }}$ strategic axis of the National Strategic Plan for the fight against STIs/HIV and AIDS in Cameroon recognizes that sensitization of the population is important in the fight against diseases. ${ }^{12}$

According to World Health Organization (WHO), ateenager is any person whose age is between $10-19$ years; ${ }^{13}$ this is a transitional period involving physical maturation, identity formation and acquisition of social roles. ${ }^{14}$ It is associated with the emergence of an awareness of sexuality and the desire to experiment and means to meet up sexual desires. ${ }^{15,16}$ If teenagers belong to the same age, they do not form a homogeneous group. To some researchers, weakness of current programs for adolescents is precisely due to the lack of recognition of the internal diversity of this population. ${ }^{17,18}$ Schooling creates a more or less long transition between childhood and adulthood; during which children or later on young adults develop skills that will enable them to succeed in life. This results in an increase in pre-marital sexual activity in acontext where there is poverty, intergenerational conflictsand lackof dialogue. ${ }^{19}$ So if sex is common in adults and adolescents, they will face dilemmas, major difficulties and obstacles. ${ }^{20}$ However, early sexual at risk behaviors will expose the individual to the likelihood of contracting an STI, HIV or early pregnancy, with the social consequences of creating a negative impact on the whole population. ${ }^{21}$

In 2013, 35 million people were living with HIV worldwide, including 24.7 million in sub-
Correspondence: Armand Tsapi Tiotsia, Department of Biomedical Sciences, University of Dschang, PO Box 67 Dschang, Cameroon.

Tel.: +237.697.838163 / +237.679.227423.

E-mail: tsapi.armand@gmail.com

Key words: Mobile Caravan Project; Awareness; STD/HIV; AIDS; Dschang.

Acknowledgments: We are grateful to the Departmental Delegation of Secondary Education of Menoua Department favorable for its approval to the implementation of this project, the various national and international partners for their enormous support to the facilitators of the project responsible for training and follow up of peer educators supervisors, to all peer educators for their availability and their sense of responsibility, the various focal points of institutions, the school principals for agreeing to the implementation of the project activities in their respective institutions.

Contributions: GR, participated in the development of the study protocol, critical reading of the manuscript to improve its content and its scientific value; ATT, recruitment of study participants, data collection and examining of the questionnaires, analysis and interpretation, manuscript design; GBDD, development of the study protocol and definition of research objectives, critical reading of the manuscript; GAFT, recruitment of study participants, data collection and examining of the questionnaires; KAT, critical review and correction of several versions of the manuscript; JRF, analysis, interpretation and validation of data; JAN, ABBS, RBM, LE, JF, critical reading of several drafts of the manuscript; MSS, development of the study protocol and definition of research objectives; interpretation and validation of data; VC, critical review of several versions of the manuscript.

Conflict of interest: the authors declare no potential conflict of interest.

Received for publication: 22 October 2016. Accepted for publication: 12 January 2017.

This work is licensed under a Creative Commons Attribution NonCommercial 4.0 License (CC BY NC 4.0).

(C)Copyright M.S. Sobze et al., 2016

Licensee PAGEPress, Italy

Journal of Public Health in Africa 2016; 7:614 doi:10.4081/jphia.2016.614

Saharan Africa. ${ }^{22}$ The prevalence in Cameroon is $4.3 \%$ and $2.8 \%$ for the western region. ${ }^{23}$ In the Dschang Health District, HIV prevalence among adolescents 15 to 19 years is $3.1 \%$ (Dschang District Health Department 2013, unpublished data), hence the usefulness of health projects such as the Mobile Caravan Project for the fight against STI's/HIV and AIDS 
designed and implemented by the PIPAD (Projet Intégré pour la Promotion de l'AutoDéveloppement) for youth awareness in secondary schools of Dschang.

The purpose of this study was to evaluate the project since its implementation in order to know its contribution to youth awareness and increase in their level of knowledge on STIs/HIV and AIDS

\section{Project's methodology and actors}

The implementation of the mobile caravan project in Dschang is ensured by a group of actors with precise roles as elaborated below:

i. Delegation of secondary education; gives authorization for access into secondary schools,

ii. PIPAD (Projet Intégré pour la Promotion de l'Auto-Développement) responsible for implementing the project;

iii. Facilitatorsmade up of PIPAD agents;

iv. Peer educator supervisors (PES) from the University of Dschang trained by the facilitators from PIPAD responsible for educating PE in secondary schools

v. Peer Educators (PE) elected by democracy in all class rooms from Form 3 of all secondary schools, responsible for educating their classmates and school mates during school breaks or free periods

vi. The principals of the different schools; give authorization and access into the schools,

vii. Teachersfrom the different schools mobilize students and work in collaboration with PES. They also act as Focal Points (FP) to PIPAD

For the Caravan project to go through, trained PES go to the Health Clubs (HC) of all secondary schools who accepted to participate in the project and educated the PE on various themes on STI's/HIV and AIDS over a given period of time. Members of the HC which are PE then educate their peers on the same themes during school breaks or free periods.

\section{Materials and Methods}

\section{Study location}

This study was carried out in the Dschang Health District (DHD) precisely in secondary schools of the area. The district's total population was about 221,031 at the end of 2015 . It has 22 health areas, 66 health facilities including 1 District Hospital and 3 day care hospitals (Saint Vincent de Paul's hospital, DH and the medical center of the University of Dschang), and 4 medicalized health centers.

\section{Study design and sampling}

A cross-sectional andanalyticstudy was carried out where all the students present at the time of study and accepted to participate were included in the study.

\section{Data collection and analysis}

Data collection was done by distributing a two page questionnaire to students who accepted to participate in all secondary schools after taking part in group or interpersonal discussions on various themes of STI's/HIV and Aids (with PES and PE or PE and classmate) for three consecutive academic years (20122013, 2013.2014 and 2014-2015), this by selfresponding and providing clarifications where necessary. At the end all the questionnaires were collected and cross checked if they were well filled and corrected immediately.

Before data was entered,scores were assigned between 0 and 100 points depending on the level of knowledge of the students. It was then analyzed after double entry to reduce any errors using the software Epi-Info 7.1.3.3 and Excel 2007, with a significance level of 0.05 .

We adopted the following scale to categorize the level of knowledge - aptitude and practices of respondents on STI's / HIV and AIDS:

- Level of knowledge - low: scale 0 (less than $50 \%$ of fair and consistent responses);

- Level of knowledge - medium: scale 1 (between 50\% and 85\% fair and consistent responses);

- Level of knowledge - high: scale 2 (over 85\% of fair and consistent responses).

\section{Ethical considerations}

The implementation of the project's activities in the institutions was preceded by obtaining administrative authorizations in compliance with national guidelines on the use of condoms in secondary schools, and an informed consent from to the adolescentsbefore filling the different questionnaires. Principles such as confidentiality and respect of anonymity were strictly followed during data collection, processing and analysis.

\section{Results}

\section{Description of the study population}

Over three years (September 2012 to March 2015)2029 students in 10 secondary schools withmean age 17 yearsbenefited from the activities of the caravan project. The adolescent age group was more represented, more than half $(58.55 \%)$ in the total sample as shown in Figure 1.

Regarding the type of school, students of private schools (56.18\%) adhered better than those from public schools, and students of second cycle (63.92\%) adhered better than those of the first cycle. Girls were more represented (56.18\%) than boys as shown in Table 1.

There was better adherence of up to $54 \%$ of students in the post test than pretest as shown in the Figure 2.

\section{Knowledge level of beneficiaries}

Based on the knowledge scale mentioned above, almost half of the respondents fell within scale 1 (50-85\% correct answers) and 25\% within scale 0 (less than $50 \%$ of correct answers). The average level of knowledge was estimated at $63.65 \%$ with a standard deviation of $23.46 \%$ (Figure 3 ).

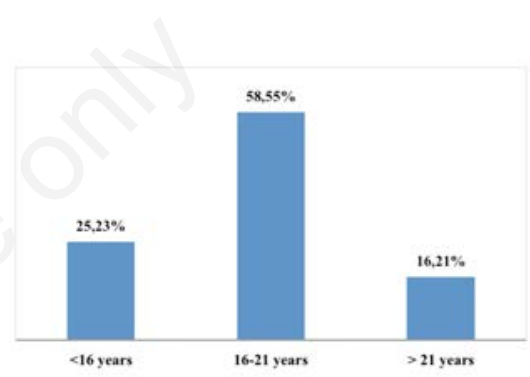

Figure 1. Distribution of beneficiaries by age.

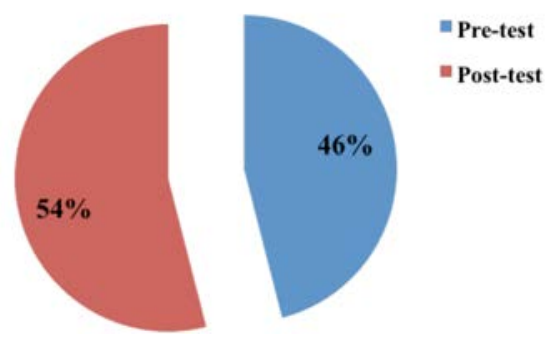

Figure 2. Level of participation in pre and post-test of the caravan project.

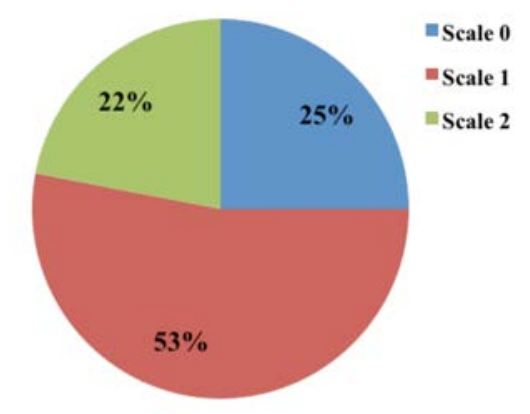

Figure 3. Distribution of students according to their level of knowledge. 
Looking the level of knowledge of students on STIs/HIV and AIDS in secondary schools in Dschang, Table 2 below gives the details with a few variables that could influence the degree of acquisition of information received by the students and those thatcould alsoinfluence their knowledgelevel using a scale graded from 0 to 2 (Table 2). More than half (53.13\%) of the beneficiaries had an acceptable level of knowledge and fell in scale 1 (50-84\%).

The evaluation of the knowledge level of students per year depending on the pre and posttest over three years of implementing the caravan project is shown in Table 3. From the figure, the number of respondents increased each year showingthe students' interestfor their health through the project. The first two years had better mobilization of students during the post-test than in the pre-test; with the exception of 2014 where the number enormously dropped.

\section{Factors affecting the degreeof students' adherence and their knowledge}

We used simple logistic regression to investigate potential factors that could affect the level of knowledge and degree of adherence of students in the project'sactivities. This was done by testing the level of knowledge with some variables in our study considered to be those of interest.

Table 4 shows the possible links between the level of knowledge and some significant variables of interest. Older students had the tendency of having a good knowledge level $(\mathrm{P}=0.04)$ than younger ones. A good knowledge level of girl/boys $(\mathrm{P}<0.05), 2^{\text {nd }}$ cycle students/second Cycle student $(\mathrm{P}<0.05)$, posttest/pre-test $(\mathrm{P}<0.05)$ and public/private schools $(\mathrm{P}=0.03)$ increased respectively when- compared. Over the years the probability also increased from $\mathrm{P}=0.04$ to $\mathrm{P}=0.006$ (Table 4).

\section{Determinants influencing the level of knowledge of students}

In order to eliminate possible confounding factors among selected variables, we used multiple logistic regressionsto adjust theage of participants considering it as a primary independent variable; with sex, study cycle, the nature of the test, the type of institution, and the first two years entering our evaluation as secondary independent variables (confounders). Table 5 shows the adjustment of the level of knowledge according to the variables of interest to our assessment. After adjustment, all the variables significantly influenced the knowledge level of students except age. There was an increase in the population of girls with a probability of them $(\mathrm{P}<0.05)$, having a higher level of knowledge than boys, an increase of the probability of having a good level of knowledge among students of the $2^{\text {nd }}$ cycle compared to those of the $1^{\text {st }}$ cycle $(\mathrm{P}=0.0004)$, an increase in the post-test the level of knowledge in the pre-test $(\mathrm{P}<0.05)$ and institutions public those private $(\mathrm{P}=0.0027)$. We also note an increase in this probability over time $(\mathrm{P}<0.05)$.

\section{Discussion}

The evaluation of the overall knowledge level of students in secondary schools on STIs / HIV and AIDS showed that $25 \%$ of students had a low level of knowledge (knowledge not acceptable) and $75 \%$ of students an acceptable level of knowledge (average: 53\%; high: 22\%). This is generally satisfactory and encouraging, because $3 / 4$ of students have an acceptable level of knowledge.

Young people aged 12-26 years benefited from the activities of the mobile caravan project against STI/HIV and AIDS in secondary schools in Dschang. The most represented age group was that of $16-21$ years $(58.55 \%$ of students). This can be explained by the fact that at this age, teens are often sexually active and are more exposed to the risk of having a sexual relationship as shown in a study by Jewkes et al. (2006) where young people aged 15-26 years responded more effectively to the health project based on the adolescent reproductive health (RH). We can also say that at this age, there is a transition between adolescence and adult hood, which make them feel concerned and gives the zeal to learn more about the reproductive health and better management ofpuberty. Also, girls would be able to count their menstrual cycle while the boys would affirmtheir manhood.

The overall level of youth participation by gender in secondary schools ( $56 \%$ girls against $44 \%$ of boys), corroborates with the study of Kim \& Watts (2005) which showed a higher female participation in RH activities. This could be explained by the fact that girls are more sensitive regarding reproductive health in relation to STI's/HIV and AIDS, experience physiological changes and would like to learn more about how to behave vis-à-vis these changes to avoid teenage pregnancy, STI's/HIV and AIDS. This could also be the reason why generally, more girls in these institutions easily integrated into the mobile caravan project against STI/HIV and AIDS. This trend of adherenceto the project is very important because it helps to introduce PMTCT early enough to the girl (future mother) and prepares her to better manage mother hood

The school participation rate by private or public type highlights the fact that private

Table 1. Overview of the study population.

\begin{tabular}{|c|c|c|c|c|c|c|c|}
\hline \multirow[t]{2}{*}{ School year } & \multirow{2}{*}{$\begin{array}{c}\text { Mean age } \pm \text { SD } \\
\text { (years) }\end{array}$} & \multicolumn{2}{|c|}{ Type of institution } & \multicolumn{2}{|c|}{ Study cycle } & \multicolumn{2}{|c|}{ Sex } \\
\hline & & Public & Private & $1^{\text {st }}$ cycle & $2^{\text {nd }}$ cycle & M & $\mathbf{F}$ \\
\hline 2012-2013 & $17 \pm 3.12$ & 291 & 350 & 255 & 386 & 289 & 352 \\
\hline 2013-2014 & $16.75 \pm 2.97$ & 345 & 331 & 222 & 454 & 273 & 403 \\
\hline $2014-2015$ & $17.30 \pm 3.19$ & 253 & 459 & 255 & 457 & 327 & 385 \\
\hline Total & $17 \pm 3.10$ & 889 & 1140 & 732 & 1297 & 889 & 1140 \\
\hline
\end{tabular}

Table 2. Level of knowledge of students based on some variables of interest.

\begin{tabular}{|c|c|c|c|c|c|c|c|c|c|}
\hline \multirow{2}{*}{$\begin{array}{l}\text { Level of } \\
\text { knowledge (\%) }\end{array}$} & \multirow[t]{2}{*}{ Population } & \multicolumn{2}{|c|}{ Type of institution } & \multicolumn{2}{|c|}{ Study cycle } & \multicolumn{2}{|c|}{ Sex } & \multicolumn{2}{|c|}{ Test type } \\
\hline & & Public & Private & $1^{\text {st }}$ cycle & $2^{\text {nd }}$ cycle & M & F & Pre-test & Post-test \\
\hline Scale $0(0-49)$ & 514 & 204 & 310 & 224 & 290 & 267 & 247 & 278 & 236 \\
\hline Scale 1 (50-84) & 1078 & 505 & 573 & 362 & 716 & 460 & 618 & 479 & 599 \\
\hline Scale $2(85-100)$ & 437 & 180 & 257 & 126 & 311 & 162 & 275 & 175 & 262 \\
\hline Total & 2029 & 889 & 1140 & 712 & 1317 & 889 & 1140 & 932 & 1097 \\
\hline
\end{tabular}


schools are globally the most represented: $56.19 \%$ of private schools and $43.81 \%$ of public schools. This shows collaboration between the caravan project and secondary schools thus promoting entrepreneurship and support to the project.

The cyclical evolution of the mobile caravan project against STI/HIV and AIDS depending on the test nature (pre-test or post-test) shows a higher proportion of participants during the post test ( $54 \%$ of students) compared to pretest ( $46 \%$ of students). This indicates that students participatedmore in the post-test because they were already informed about the pretest and other themes developed with them before the post-test.

The level of knowledge of young adolescents in secondary schools of Dschang significantlyincreased from 2012-2015, this could be explained by the fact that adolescents participate every year in the project thereby accentuating their knowledge and awareness and sensitizing their classmates and peers on prevention of STI/HIV and AIDS; on the other hand, this could also be because the students accept and integrate in a participative manner in the project.This makes them actively involved satisfied. Finally we can see a successful caravan project since it will increasingly reaching the goals on primary prevention (PP).

Over the years, the proportion of adolescents with a higher level ofknowledge in (scale 2 ) increased. This could be explained by the participatory method of the project: tools such as VIPP cards (Visualisation Intégrée au Processus Participatif) are used.

The post-tests used to establish the values of the indicators of success in achieving participatory process of young people and their integration project. This shows the project's acceptance in secondary schools by young people. They also help evaluate the action of the pre-tests. We noted that the post-test significantly accentuated the efforts of the pre-test. This goes in line with the project vacation without AIDS carried out in Cameroon, ${ }^{23}$ shows that from one year to another, the project is spread and occupies a place increasingly important in the fight against STI/HIV and AIDS.

Overall, students of secondary schools of general education have more knowledge on STI/HIV and AIDS and in RH, including ARHthan those doing technical education. This could be due to the fact that in general education, there is introduction of basic lessons on reproductive health such as human biology (consist of aspects like physical development risk factors of sexually transmitted infections, HIV and AIDS and their means of prevention).In technical institutions, disciplines based on the RH in the second cycle are almost absent while priority is given to professional disciplines such as carpentry, masonry, sewing, in the Industry and dressing. Nevertheless there exist the SEF sector (Social Economy and Family) which should provide acceptable level of knowledge on RH in technical schools but is not of interest to the students. The present study does not allow us to assess the causes of the non-interest; however, this would be considered in future assessments to better understand the challenges these adolescents face with STI's/HIV and AIDS. Public institutions have an acceptable level of knowledge higher than those of private institutions. This approximates the results of

Cameron et al. (2005), who describes the possible rigor of education in these institutions.

Abstinence is promoted in secondary schools, reducing the risk of early and unwanted pregnancies, abortions, promiscuity, early sex and loss of virginity, STIs and HIV/AIDS.

\section{Conclusions}

The Caravan Mobile project against STI/HIV and AIDS in the Dschang Municipality has

Table 3. Level of knowledge of evolution based on years and pre/post test.

\begin{tabular}{cccc} 
Year & Nature of test & Level of knowledge & Effective \\
2012 & Pre-test & Scale 0 & 89 \\
& & Scale 1 & 121 \\
& & Scale 2 & 11 \\
& Post-test & Scale 0 & 119 \\
& & Scale 1 & 268 \\
& & Scale 2 & 33 \\
2013 & Pre-test & Scale 0 & 111 \\
& & Scale 1 & 141 \\
& & Scale 2 & 95 \\
& Post-test & Scale 0 & 62 \\
& & Scale 1 & 197 \\
& & Scale 2 & 70 \\
\hline 2014 & Pre-test & Scale 0 & 78 \\
& & Scale 1 & 217 \\
& & Scale 2 & 69 \\
& Post-test & Scale 0 & 59 \\
& & Scale 1 & 137 \\
& & Scale 2 & 159 \\
\hline
\end{tabular}

Table 4. Relationship between the level of knowledge and some factors of influence.

\begin{tabular}{lccc} 
& Odds ratio & $95 \%$ CI & P-value \\
Age & 1.03 & 1.00 to 1.07 & $0.04^{*}$ \\
Gender (Male/Female) & 0.64 & 0.53 to 0.79 & 0 \\
\hline Cycle of studies (2 ${ }^{\text {nd }}$ cycle/cycle 1) & 1.63 & 1.32 to 1.99 & 0 \\
Nature test (post-test/pre-test) & 1.6 & 1.27 to 1.90 & 0 \\
\hline Type of school (private/public) & 0.8 & 0.65 to 0.98 & $0.03^{*}$ \\
Year $(2013 / 2012)$ & 1.4 & 1.10 to 1.77 & $0.0062^{*}$ \\
\hline Year $(2014 / 2012)$ & 2.09 & to 2.69 & 0
\end{tabular}

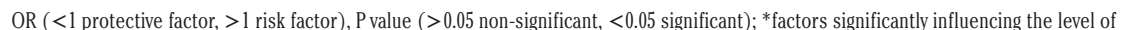
knowledge.

Table 5. Adjusting the level of knowledge with the variables of interest in the study.

\begin{tabular}{lccc} 
& Adjusted odds ratio & $95 \%$ CI & P-value \\
Age & 1.02 & 0.99 to 1.06 & 0.2104 \\
Gender (Male/Female) & 0.61 & $0.50-0.75$ & 0 \\
\hline Cycle of studies (2nd cycle/cycle 1) & 1.49 & 1.19 to 1.86 & $0.0004^{*}$ \\
Nature test (post-test/pre-test) & 1.69 & 1.37 to 2.09 & 0 \\
\hline Type of school (private/public) & 0.72 & 0.58 to 0.89 & $0.0027^{*}$ \\
Year (2013/2012) & 1.47 & 1.14 to 1.88 & $0.0026^{*}$ \\
\hline Year (2014/2012) & 2.38 & 1.83 to 3.08 & 0 \\
\hline
\end{tabular}

OR ( $<1$ protective factor, $>1$ risk factor $)$, P value $(>0.05$ non-significant, $<0.05$ significant); $*$ factors significantly influencing the level of knowledge. 
greatly contributed to youth awareness in secondary schools in Dschang. However, the need of subsidies is a prerequisite for the sustainability of its activities; it is important that further evaluations of this project are carried out to boost the results thereby reducing the risks of early pregnancy, irresponsible parenthood and new infections in HIV/STI and AIDS among youth through awareness.

\section{References}

1. Rochat P. Five levels of self-awareness as they unfold early in life. Consciousness and cognition 2003;12:717-31.

2. Youssouf T, Rajaa B, Ahdoulad L, et al. Potential sexual exposure to HIV: experience of the infectious diseases unit of Casablanca and literature review. Elsevier Masson SAS 2014;43:215-8.

3. Adeothy-Koumakpaï S.HIV infection in adolescents living in developing countries. Arch Pediatr 2002;9:1117-9.

4. Samkange-Zeeb FN, Spallek L, Zeeb H. Awareness and knowledge of sexually transmitted diseases (STDs) among school-going adolescents in Europe: a systematic review of published literature. BMC Public Health 2011;11:1.

5. Arora A, Siddiqui Sana DH. Awareness of fitness training principles amongst fitness trainers. Int J Sci Res 2014;3:1204-7.

6. Bonierbale M, Enel P, Alexandre A, et al. HIV screening during regional erotic industry shows: an innovative French approach. Sexologies 2016;25:24-30.

7. Djadou KE, Kanassoua K, Douti K, et al. Morbidity and mortality in teenagers at Tsévié's hospital (Togo). J Pediatr Puericult 2010;23:191-7.

8. Dinev T, Hu Q. The centrality of awareness in the formation of user behavioral intention toward protective information technologies. J Assoc Informat Syst 2007;8:386408.

9. Morin M, Potin J, Perrin C, et al. [Antenatal screening for HIV: knowledge, attitudes, beliefs and practices of pregnant women. Analysis of current practices and the impact of setting up an informative brochure]. J Gynecol Obstet Biol Reprod (Paris) 2011;40:216-24. [Article in French]

10. Morris JL, Rushwan H. Adolescent sexual and reproductive health: the global challenges. Int J Gynecol Obstet 2015;131:S402.

11. Ministère de la Santé Public du Cameroun. Stratégie sectorielle de santé 2001-2015; 2009. Available from: http://cm$\mathrm{mins}$ an te-drh.com/s ite/images/ stories/SSS_2001_2015_Doc_final.pdf

12. Ministère de la Santé Public du Cameroun. Plan Stratégique national de lutte contre le VIH, le SIDA et les autres IST 2011-2015. Yaoundé: ministère de la Santé Publique; 2009. Available from: https://www.ilo.org/dyn/natlex/docs/ELECTRONIC/99129/118193/F-746502152/CMR99129.pdf

13. World Health Organization. Guidelines for research on reproductive health involving adolescents; preparing a Project Proposal, Guidelines and Forms (Fourth Edition). Geneva: UNDP/UNFPA/WHO/World Bank Special Programme of Research, Development and Research Training in Human Reproduction; 2003. Available from: http://www.gfmer.ch/SRH-Course2011/research-methodology/pdf/WHO-proposal-guidelines-forms-2003.pdf

14. Gage AJ. Sexual activity and contraceptive use: the components of the decision-making process. Stud Fam Plann 1998;29:15466 .

15. Dehne KL, Riedner G. Adolescence - A dynamic concept. Reprod Health Matters 2001;9:11-5.

16. Tolman DL. Doing desire. Teenager girl's Struggles for/with sexuality. Gender Soc 1994;8:324-42.

17. Mac Phail C, Campbell C. I think condoms are good but, I hate those things: condom use among teenagers and young people in a Southern African township. Soc Sci Med 2001;52:1613-27.

18. Erulkar SA, Mekbib TA, Negussie S, Tsehai G. Differential use of adolescent reproduc- tive health programs in Addis Ababa, Ethiopia. J Adolesc Health 2006;38:253-60.

19. Afenyadu D, Goparaju L. Adolescent sexual and reproductive health behavior in Dodowa, Ghana. Centre for development and population activities (CEDPA): USAID; 2003.

20. Guiella G, Woog V. Santé sexuelle et reproductive des adolescents au Burkina Faso: Résultats d'une enquête nationale en 2004. Occasional Rep 2006;21:49-90.

21. Maina Ahlberg B, Jylkäs E, Krantz I. Gendered construction of sexual risks: implications for safer sex among young people in Kenya and Sweden. Reprod Health Matters 2001;9:26-36.

22. Joint United Nations Programme on HIV/AIDS (UNAIDS). Global report: UNAIDS report on the global AIDS epidemic 2013. Geneva: UNAIDS, 2013. According to the UNAIDS' estimate the number of new infections in the region increased from; 2015. (21): 22,000-47,000. Available from: http://www.unaids.org/sites/default/ files/media_asset/UNAIDS_Global_Report _2013_en_1.pdf

23. Comité National de Lutte contre le Sida (CNLS) et ONUSIDA. Rapport national de suivi de la déclaration politique sur le VIH/Sida au Cameroun ; Global Aids Response Progress (GARP). CNLS; 2014. Available from:

http://www.unaids.org/sites/default/files/country/documents/CMR_narrative_report_201 4.pdf

24. Jewkes R, Dunkle K, Koss MP, et al. Rape perpetration by young, rural South African men: Prevalence, patterns and risk factors. Soc Sci Med 2006;63:2949-61.

25. Kim J, Watts CH. Gaining a foothold: tackling poverty, gender inequality, and HIV in Africa. BMJ 2005;331:769-72.

26. Cameron KA, Salazar LF, Bernhardt JM, et al. Adolescents experience with sex on the web: results from online focus groups. $\mathrm{J}$ Adolesc 2005;28:535-40. 